\title{
doispontos:
}

\section{O saber imediato e mediato: crença e saber? Um “diálogo" entre Jacobi e Hegel'}

\author{
The immediate and mediate knowledge: belief or knowledge? A "dialogue" between Jacobi and Hegel
}

Juliana F. Martone

Doutoranda do Departamento de Filosofia da Universidade de São Paulo - USP

juliferraci@gmail.com

Resumo: A presente exposição tem como ponto de partida a leitura hegeliana de Jacobi, exposta na Enciclopédia das ciências filosóficas de 1827-1830, a respeito do saber imediato e, consequentemente, da oposição entre crença e saber. A finalidade da comparação é evidenciar o que Jacobi entende por "saber imediato", em oposição a um saber mediato (ciência), e mostrar por que a crença não é meramente subjetiva - como foi, e ainda largamente interpretado - e por que individualidade não é sinônimo de subjetividade, como queria Hegel. Afinal, as dificuldades e equívocos da leitura hegeliana servem para compreender melhor os próprios conceitos de Jacobi.

Palavras-chave: F. H. Jacobi; Hegel; saber imediato; subjetividade.

Abstract:The following essay has as its starting point the Hegelian analysis, exposed in his Encyclopedia of philosophical sciences (1827-1830), concerning Jacobi's notion of immediate knowledge and, therefore, the opposition between belief and knowledge. Such comparison intends to shed light on Jacobi's definition of "immediate knowledge", as opposed to a mediate knowledge (science), and show that belief cannot be subjective - as it was and still is widely conceived -, thus why individuality isn't the same as subjectivity, such as sustained by Hegel. The difficulties and mistakes of the Hegelian interpretation contribute to a further comprehension of Jacobi's own concepts.

Keywords: F. H. Jacobi; Hegel; immediate knowledge; subjectivity.

${ }^{1}$ Este artigo foi realizado com o apoio da Fundação de Amparo à Pesquisa do Estado de São Paulo (FAPESP), n ${ }^{\circ}$ do processo: 2017/03803-8. 
Jacobi é comumente - e às vezes exclusivamente - conhecido por sua denominada Glaubensphilosophie (filosofia da crença), e muita tinta foi gasta para tratar desse assunto que já dividia seus contemporâneos. A noção jacobiana de saber imediato (crença) como alternativa à hegemonia do saber reflexivo enquanto unidade perfeita e acabada marcou sua época e é, sem dúvida, um dos maiores legados da obra do filósofo alemão, não apenas enquanto nova via aberta num ambiente marcado por certo "entusiasmo lógico", mas como censura a ele e aos seus prolongamentos: o idealismo e as filosofias do eu. Ao redor do conceito de crença orbitam diversos outros pressupostos, como as noções de certeza, razão, causalidade, possibilidade e realidade e, é claro, o próprio sentido e significado da filosofia.

Reflexo da presença marcante do topos do saber imediato no ambiente alemão, é sua retomada por Hegel muito tempo depois, na Enciclopédia das ciências filosóficas de 1827 e 1830, mais precisamente na introdução da obra. Seu intuito é claro: descrever o percurso do pensamento rumo à objetividade. Esse movimento começa na sentença de morte da metafísica clássica enquanto tentativa de explicar a verdade dos objetos reais pelo mero pensamento ou, ainda, enquanto acredita que a determinação das coisas no pensamento seja igual a das coisas mesmas. Nada mais natural que Hegel siga o conselho kantiano e empunhe a bandeira da luta contra os "dogmáticos", para os quais verdade e falsidade se limitariam às proposições lógicas, isto é, a uma simples predicação no interior do pensamento e das coisas produzidas por ele.

O segundo estágio descrito é o empirismo, a antítese da metafísica, que se refere apenas ao exterior, à experiência, e nega tudo aquilo que foge à percepção, portanto nega o suprassensível. Um subcapítulo desse segundo momento é, segundo Hegel, o criticismo, uma espécie de síntese entre dogmatismo e ceticismo, na medida em que se mantém no "chão" da experiência em relação ao conhecimento, mas reconhece sua insuficiência. Em outras palavras, reconhece que universalidade e necessidade devem ser encontradas na experiência, contudo não provêm do empírico mesmo. Em suma, reconhece o lado necessário da subjetividade, da "espontaneidade" do pensamento a priori e do incondicionado, algo que tem em comum com a velha metafísica, embora se distancie dela à medida que identifica seu erro: misturar e colocar determinações empíricas no lugar de determinações do pensamento. Na filosofia crítica sobraria, então, algo da experiência para o conhecimento, mas este é estruturado pelo sujeito; desaparecem as coisas e restam os fenômenos. Em virtude disso, o criticismo seria um "empirismo metafisicante" (HEGEL, 1970, \$ 60).

No $\$ 51$, Hegel ressalta o mérito do esforço kantiano para mostrar que ser e pensamento são diferentes e acrescenta que essa distinção teria a finalidade de evitar, entre outras coisas, a passagem do pensamento de Deus para a certeza da existência de Deus, ainda que não a impeça por completo, ${ }^{2}$ ou ainda, teria a finalidade de evitar qualquer tentativa de demonstração da existência de Deus. É aí que desponta Jacobi - embora ainda não citado nominalmente - como símbolo dessa passagem "proibida", do "retrocesso", ou da tentativa de afirmar "a inseparabilidade do pensamento de Deus de seu ser" no conhecimento ou saber imediato (crença). Hegel insinua que Jacobi é um metafísico? Veremos como o realismo jacobiano e o conhecimento imediato ou crença pertencem a um âmbito antimetafísico por excelência e por que essa leitura de Hegel é extremamente problemática.

\section{Individualidade é subjetividade?}

Ainda de acordo com Hegel, apesar de algumas semelhanças, na filosofia de Kant "finitude e subjetividade têm uma forma objetiva do conceito; a jacobiana, ao contrário, transforma, de modo inteiramente subjetivo, a

\footnotetext{
${ }^{2}$ Essa talvez seja uma das mais importantes contribuições de Kant para a filosofia alemã, a saber, ter mostrado que a existência não é predicado, mas "posição absoluta", não é "complemento da possibilidade" como afirmava Wolff. Com isso, ele acusa os "dogmáticos" e a metafísica de não distinguir lógica e realidade, o ser lógico da cópula e o ser da existência. A famosa dissertação kantiana que trata desse problema - comentada e muito apreciada por Jacobi - é o texto de 1763 O único fundamento possivel de uma demonstração da existência de Deus.
} 
subjetividade em individualidade" (HEGEL, 2007, p. 69). ${ }^{3}$ Aqui reside o equívoco ou a distorção fundamental que marcará a leitura hegeliana da obra de Jacobi: tomar individualidade por subjetividade. Desde o texto Glauben und Wissen (publicado anônimo em julho de 1802 no Kritisches Journal der Philosophie, editado por ele e Schelling), Hegel apresenta o pensamento jacobiano, sobretudo a noção de crença, com o estigma de uma filosofia subjetivista. Isso, porque, assim como em Kant, a esfera da filosofia jacobiana seria o "ser absoluto" da oposição entre finitude/saber, de um lado, e sobrenatural/infinitude, de outro. Jacobi não teria considerado outro ponto de vista, senão o da "finitude infinita" (endliche Unendlichkeit) e teria colocado a infinitude ou o incondicionado num "para-além", na crença. "Para ambas as filosofias, portanto, o absoluto verdadeiro é um para-além na fé [crença] ou na sensação e nada para a razão cognoscente” (HEGEL, 2007, p. 126). A subjetividade dessas filosofias - que, de resto, pouco têm em comum - se localizaria no fato de que o positivo está sempre na sensibilidade (na razão "afetada sensivelmente"), portanto apenas na razão humana finita.

Individualidade é uma das principais determinações do conceito jacobiano de pessoa: um sujeito concreto e real com todas as suas características particulares. Individualidade implica necessariamente a vida, ser e estar no mundo real e concreto, implica determinação e, acima de tudo, substancialidade. ${ }^{4}$ Inversamente, segundo Jacobi é a noção de transcendental que conduz ao subjetivismo desmedido, ao idealismo ou ao niilismo, pois despe a pessoa de suas características, abstrai toda e qualquer qualidade para postular uma instância vazia, ${ }^{5}$ valendo-se da regra "o que é universal, necessário e apodítico é objetivamente válido" e transformando a estrutura a priori do sujeito em geral em estrutura objetiva. A filosofia transcendental inverte os termos e seus significados, hipostasia a mera subjetividade.

Para Jacobi, com a denominada virada copernicana, é Kant quem produz essa reviravolta. Escrevendo a Matthias Claudius, ${ }^{6}$ ele constata: "Você viu como a filosofia apriorística formal (pura filosofia racional, lógica) traz à luz a filosofia material a priori (pura física, metafísica) e como esta é apenas uma investigação mais profunda daquela, é lógica transcendental. Portanto, você não poderá se incomodar se agora encontrar denominado subjetivo aquilo que antes era objetivo, e vice-versa." (JWA 2,1, p. 136) Ou, ainda, em outras palavras:

Expondo a primeira proposição principal [os objetos não podem ser causa das representações enquanto tais], Kant a desmembra, ou melhor, a deduz de tal modo, que se vê claramente que a pura faculdade de representação deve ser uma faculdade de pensar um objeto em geral, isto é, a priori. (...) Apenas o espírito pode compreender; apenas ele pode transformar o múltiplo da sensação em objetos; portanto os objetos estão, segundo a forma, apenas em nós, tal como, segundo a matéria, enquanto sensação, também só podem estar em nós (JWA 2,1, p. 124).

A crítica de Jacobi se refere sobretudo ao modo como ele interpreta a empreitada ${ }^{7}$ kantiana de transformar o conteúdo (matéria a priori) em uma espécie de forma e a própria forma (lógica geral) em "forma da

\footnotetext{
3 "Resulta do que dissemos até agora que a filosofia kantiana se contrapõe à jacobiana, na medida em que, no interior da esfera comum a ambas, a kantiana põe a subjetividade e a finitude absolutas em uma abstração pura e, com isso, ganha a objetividade e a infinitude do conceito; a jacobiana, entretanto, não assume a finitude ela mesma no conceito, mas faz dela princípio como finitude finita [endliche Endlichkeit], como contingência empírica e consciência dessa subjetividade” (HEGEL, 2007, p.125-126).

${ }^{4}$ Jacobi utiliza a expressão "personalidade objetiva”, isto é, a identidade real do meu sujeito, em oposição a uma identidade abstrata.

${ }^{5}$ A passagem completa diz: "Volta-te agora para ti mesma; separa-te no pensamento por um segundo de todas as tuas representações sensíveis, de todas experiências, sensações, juízos e inclinações que se referem a essas representações: o que resta de teu ser após um tal esvaziamento? Nada além de uma representação completamente indefinida de um princípio vital puro sem singularidade, sem individualidade, sem qualquer traço do ser do qual tens agora a sensação de que é tua pessoa, de que é Ernestine.

Portanto, o que garante tuas representações, conceitos, juízos e inclinações, garante também tua existência pessoal e efetiva, e aquilo que os coloca em perigo, coloca também tua existência em perigo, te atinge como a morte" (JWA 5,1, p. 204).

${ }^{6}$ Cartas enviadas por Jacobi a Matthias Claudius entre 2 de novembro e 21 de dezembro de 1791. Cf.: JWA 2,2, p. 460.

${ }^{7}$ Ver também o texto de Jacobi Sobre o empreendimento do criticismo de transformar a razão em entendimento e dar à filosofia em geral um novo propósito ("Über das Unternehmen des Criticismus, die Vernunft zu Verstande zu bringen, und der Philosophie überhaupt eine neue absicht zu geben) de 1802. In: JWA 2,1, p. 261-274.
} 
forma”, já que, aquilo que se denomina material, é insuficiente para fundar qualquer objetividade e não se refere a nada do mundo efetivo.

O critério de necessidade e apodicidade para constituir a objetividade faz do transcendental, do a priori, a objetividade por excelência e reduz o particular (individual) à simples subjetividade, como afirmava Hegel no início. Em carta a Kant de novembro de 1789, Jacobi se afasta do criticismo dizendo que, para resolver a contradição da razão consigo mesma e criar um sistema da filosofia pura, o filósofo de Königsberg afirma que a natureza (o representado em geral) toma a forma de nossa faculdade de representar, "eu, ao contrário, me inclino mais a procurar a forma da razão humana na forma universal das coisas" (JBW, I/8, p. 322). ${ }^{8}$ Tal oposição se traduz também em termos de objetividade-subjetividade. Para Jacobi, a objetividade está no mundo concreto, "na forma das coisas", para Kant e seus seguidores no plano transcendental, dado que o mundo empírico e "real" não tem mais voz nem lugar numa filosofia que não se ocupa mais de objetos. O confronto entre pessoal e transcendental serve para evidenciar dois registros absolutamente distintos em que operam as filosofias kantiana e jacobiana; uma no âmbito da possibilidade a priori em geral (filosofia transcendental), a outra no âmbito da existência, da experiência particular a posteriori. ${ }^{9}$

No Cânone da razão pura, Kant diferencia dois modos de tomar algo por verdadeiro (Fürwahrhalten): um meramente subjetivo - e, portanto, particular -, denominado persuasão e outro objetivo e universal, denominado convicção. "A persuasão é uma simples ilusão, porque o fundamento do juízo, que reside unicamente no sujeito, é considerado objetivo. Por isso, semelhante juízo possui também apenas um valor individual e o tomar por verdadeiro (Fürwahrhalten) não se deixa comunicar" (KANT, KrVA820-B848). ${ }^{10}$ Aqui, individualidade é sinônimo de incomunicabilidade, subjetividade, e produz, no máximo, uma opinião não universalizável. Ao contrário, uma suposição objetiva que leva ao saber deve ser comunicável, já que a verdade se encontra na concordância de todos os juízos em um princípio comum (o objeto) independentemente da diversidade dos sujeitos, ou seja, de sua individualidade. Assim, personalidade ou individualidade significa limitação, e a ciência, por sua vez, é o único grau suficiente de Fürwahrhalten. "A suficiência subjetiva chama-se convicção (para mim próprio); a suficiência objetiva, certeza (para todos)" (KANT, $\mathrm{KrV}$ A822-B850). ${ }^{11}$ É evidente que a opinião (meinen) será banida dos juízos da razão pura, pois o critério de verdade (saber) é a universalização e a necessidade. Tal critério só pode ser a priori, uma vez que a experiência diz apenas que algo é, mas não que é necessariamente assim e não de outro modo (princípio de razão), sendo insuficiente para a conviç̧ão e para o saber.

Portanto, é apenas na supressão da singularidade ou individualidade, na supressão da diferença que encontramos a verdade; apenas naquilo que é idêntico entre os sujeitos encontramos o solo firme do saber. $\mathrm{Na}$ Reflexão 5129, as palavras de Kant são ainda mais explícitas: "Uma ciência de coisas em geral abstrai efetivamente de toda diferença e determinação das coisas como objetos e, portanto, trata apenas da razão pura: filosofia transcendental". ${ }^{\prime 2} \mathrm{O}$ saber se completa exclusivamente na passagem do individual (subjetivo) para o universal (objetivo), na transformação do sujeito-pessoa em sujeito-transcendental ou, o que é o mesmo, na eliminação da substancialidade e determinação das coisas e do sujeito para dar lugar a coisas e a um sujeito em geral. Assim, a objetividade não se refere a objetos, a um mundo fático ou efetivo, mas à condição de possibilidade universal e necessariamente válida para qualquer experiência. A noção de pessoa

\footnotetext{
${ }^{8}$ Jacobi recebe uma carta de Kant em 30 de agosto de 1789 e lhe responde em 16 de novembro do mesmo ano.

${ }^{9}$ Isto é, em Jacobi a objetividade se refere a objetos e à experiência, em Kant, ao objeto construído pelo sujeito (fenômeno).

${ }^{10}$ Disponível em: <https://korpora.zim.uni-duisburg-essen.de/kant/aa03/532.html>. Acesso em: 13 de julho de 2020.

${ }^{11}$ Disponível em: <https://korpora.zim.uni-duisburg-essen.de/kant/aa03/533.html >. Acesso em: 13 de julho de 2020.

${ }^{12} 5129 . \varphi 2$ ? $\chi-\psi$ ? M 2. E II 120I. In M 5: Eine Wissenschaft von Dingen überhaupt abstrahirt wirklich von allem Unterschiede und Bestimmungen der Dinge als Gegenstände und handelt also bloß von der reinen Vernunft: transscendentalphilosophie. Disponível em: <https://korpora.zim.uni-duisburg-essen.de/kant/aa18/100.html>. Acesso em: 13 de julho de 2020.
} 
se torna inadequada para exprimir a necessidade e a universalidade das estruturas a priori epistemológicas do sujeito formador da experiência.

Jacobi faz o percurso inverso: todo Fürwahrhalten que não provém de princípios racionais é crença, assim toda convicção mediante esses mesmos princípios racionais deve provir da crença (JWA 1,1, p. 116). Dito de outro modo, os próprios princípios racionais precisam de um fundamento, que por sua vez não pode ser um novo princípio e assim ao infinito, portanto estão fundados na crença. A personalidade é um dos fundamentos de sua filosofia, e a individualidade deve ser a fonte de todo saber, pois, sem ela, restam apenas entes de razão; temos adjetivos sem substantivos, como diz o texto da carta a Jean Paul (16 de março de 1800).

Individualidade é um sentimento fundamental; individualidade é a raiz da inteligência e de todo conhecimento;
sem individualidade não há substancialidade, sem substancialidade, em toda parte nada. (...) Puro egotismo é puro
este mesmo sem o este. - Este ou aquele é necessariamente sempre um indivíduo. Portanto, substancialidade está
absolutamente no fundamento da identidade, e a individualidade no da substancialidade. Consciente é um adjetivo,
não pode ser pensado sem substantivo, e esse substantivo é aquilo que se apresenta invisivelmente no sentimento
da identidade. A personalidade do homem é completamente impensável como um mero vaivém (Schweben) da
síntese, é impossível ser demonstrada como um produto no tempo, como algo que surgiria primeiramente pela
reflexão (Besinnung). Eu, Fr. H. Jacobi, me reconheço como tal sem qualquer nota característica, imediatamente,
por força de minha substância... (JBW, I/12, p. 207-208).

Se para Kant devemos superar (abstrair) a mera efetividade para buscar suas condições numa esfera anterior que a viabiliza, para Jacobi o plano da efetividade mesma é o único território possível da filosofia. $\mathrm{O}$ assim chamado realismo jacobiano se caracteriza pela permanência num mundo empírico-substancial e tematiza sobretudo o âmbito pré-reflexivo, anterior à especulação, que lhe serve como fundamento, denominado crença ou saber imediato, um saber cuja verdade é "índice de si mesma". Para Jacobi, não se trata então de erigir um sistema do saber, porque algo "que é necessariamente assim e não de outro modo" escapa ao conhecimento humano e não é dado nele de modo conceitual; o homem só pode estar certo de que algo é. Sendo assim, ele sustenta o exato oposto do que afirma Kant sobre o saber e a opinião: a crença enquanto verdadeiro saber imediato é incomunicável mediante conceitos, e essa é justamente sua força e sua superioridade. Afinal, "a convicção por razões é uma certeza de segunda mão, funda-se na comparação, e jamais pode ser completamente certa e perfeita. Razões são apenas notas características da semelhança com uma coisa da qual estamos certos. A convicção que elas geram provém da comparação e jamais pode ser completamente certa e perfeita" (JWA 1,1, p. 115-116).

Por isso, esse tipo de saber mediato é denominado conhecimento de segunda mão ou instrumental, porque percorre sequências de raciocínios "silogisticamente", prossegue de condição em condição mecanicamente e nunca atinge o incondicionado (seu resultado teológico coerente seria o deísmo ou o ateísmo). Diferentemente de muitos de seus contemporâneos e de outros filósofos - como, por exemplo, de Espinosa, que recusavam apenas a passagem do infinito ao finito -, Jacobi recusa também a passagem do finito ao infinito pelo mero pensamento; contesta que a ciência possa vencer o mecanismo e alcançar Deus ou o suprassensível através do próprio mecanismo, isto é, de modo imanente. Para tanto, será preciso um salto mortale.

Hegel tem razão quando afirma que "de acordo com isso, explicar e compreender significa mostrar algo como mediado por outro; e, com isso, todo conteúdo é apenas particular, dependente e finito; o infinito, o verdadeiro, Deus estão fora do mecanismo de tal relação, à qual o conhecimento se limita" (HEGEL, 1970, $\$ 62$, p. 149). O pensamento seria então uma atividade de "finitizar". Diferentemente de Kant, em Jacobi a crença nas coisas e no suprassensível deve ser positiva e, embora o entendimento não possa afirmar com certeza que Deus existe (uma demonstração da existência de Deus é absolutamente impossível), o sentimento afirma sua existência como fato objetivo, como "isso é" (Es ist). 
A concepção de ciência como conhecimento especulativo discursivo mediato significa que a especulação é a mera habilidade observadora de perceber relações de maneira clara, de formular o princípio de contradição e julgar de acordo com ele. Demonstrar é proceder por proposições idênticas, é comparar semelhanças. Contudo, toda prova pressupõe algo já provado: a certeza imediata da crença, uma revelação. Jacobi busca um novo fundamento para o saber que não seja uma síntese intelectual (intuição intelectual) e que não seja resultado do ato de combinar e compor. Somente o fato efetivo concede validade ao saber mediato e às representações, ele é o limite que se impõe ao homem e deve bastar para o verdadeiro realista. "Como um realista convicto pode nomear o meio pelo qual a certeza dos objetos externos, enquanto coisas em si, é comunicada? Ele não tem nada no qual possa apoiar seu juízo a não ser a própria coisa; nada além do fato de que há coisas realmente diante dele" (JWA 2,1, p. 32). Portanto, a existência de uma coisa fora de nós é a própria demonstração de sua existência, e deve permanecer incompreensível o fato de percebermos uma tal existência (JWA 2,1, p. 33). Tal fato é denominado revelação, isto é, algo que se manifesta imediatamente de maneira inexplicável, mas que deve ser aceito. É o que diz a famosa passagem endereçada a Moses Mendelssohn por ocasião da polêmica sobre o espinosismo do finado Lessing:

\begin{abstract}
Caro Mendelssohn, todos nós nascemos na crença e devemos permanecer na crença, tal como todos nós nascemos em sociedade e devemos permanecer em sociedade [Totum parte prius esse necesse est]. Como podemos pretender a certeza, se a certeza não nos for conhecida de antemão, e como ela pode nos ser conhecida senão por meio daquilo que já conhecemos com certeza? Isso nos leva ao conceito de uma certeza imediata, que não apenas prescinde de quaisquer razões, mas que exclui absolutamente todas as razões e é única e exclusivamente a própria representação que coincide com a coisa representada (portanto, tem seu fundamento em si mesma). A convicção por razões é uma certeza de segunda mão, funda-se na comparação e jamais pode ser completamente certa e perfeita (JWA 1,1, p. 115).
\end{abstract}

Jacobi concorda com Kant que apodicidade e completa necessidade são possíveis apenas em sentenças idênticas (no chamado saber mediato) e que a afirmação da existência de coisas fora de mim jamais será apodítica neste mesmo sentido. "Assim, o idealista, amparado nessa diferença, pode necessariamente me conceder que minha convicção na existência de coisas fora de mim é apenas crença” (JWA 2,1, p. 9-10). Porém, a crença, mesmo incomunicável e intraduzível em meros conceitos, é o único lugar do verdadeiro. Jacobi não rejeita a ciência per se, mas apenas nega que ela possa propiciar a base da certeza e da verdade, já que seu fundamento não está nela mesma. A comparação com a Doutrina da Ciência de Fichte esclarece muito bem essa pretensão ex negativo:

Então nós dois queremos, com igual seriedade e dedicação, que a ciência do conhecimento - que é uma só em todas as ciências; é a alma do mundo do mundo cognoscível - se torne perfeita: apenas com a diferença de que voce [Fichte] o quer para que o fundamento de toda verdade se mostre subjacente na ciência do saber; eu, para que seja evidente o fundamento: o verdadeiro mesmo está necessariamente fora dela [ciência] (JWA 2,1, p. 201).

E como o fundamento da ciência não está nela mesma, isto é, não está no entendimento, na reflexão ou especulação, não pode haver uma filosofia imanente, "de uma peça só" (como será caracterizado o idealismo ou o espinosismo). Em suma, desaparece a noção de filosofia como um sistema do saber que constrói tudo a partir de si, desaparece a exigência mesma feita pelos filósofos do sistema e notoriamente proferida por Hegel:

Um filosofar sem sistema não pode ser nada de científico; também porque um tal filosofar por si exprime, antes, um modo de sentir (Sinnesart) subjetivo, ele é contingente quanto a seu conteúdo. Um conteúdo se justifica apenas como momento da totalidade, mas fora dele é um pressuposto infundado ou tem uma certeza subjetiva; deste modo, muitos escritos filosóficos limitam-se a exprimir apenas modos de sentir e opinões (HEGEL, 1970, \$ 14, p. 59-60).

Nas inequívocas palavras de Hegel, o que garante a cientificidade e objetividade da filosofia é sua forma sistemática como um momento da totalidade, isto é, em função do todo, exatamente o que Jacobi recusa e o que lhe rende o rótulo de "subjetivista". Tomando singularidade por subjetividade, Hegel descreve a posição de Jacobi - e de outros que, como ele, recusam uma filosofia sistemática - como um simples "modo de sentir ou opinião", indigna do "saber" e da "filosofia". Em vista desse tipo de concepção, Jacobi 
assume abertamente que sua filosofia é pessoal (subjetiva segundo a leitura hegeliana ou kantiana), mas vê nisso sua vantagem em relação a uma filosofia que pretende alcançar uma verdade universal vazia, a uma filosofia da mera letra:

\begin{abstract}
Nunca foi meu objetivo apresentar um sistema para a escola; meus escritos surgiram da minha vida mais íntima, ganharam uma sequência histórica, de certo modo não os escrevi eu mesmo, não voluntariamente, mas movido por uma força maior, irresistível. Se reflexão e comunicação desse tipo são pessoais, minha filosofia é certamente pessoal; mas o mesmo se aplica a todos, aos quais sua filosofia é religião; a todos que aspiram não a uma verdade universal - um contrassenso, como o é uma existência ou realidade universais -, mas sim a uma verdade determinada, que satisfaça mente e coração. Ao mesmo tempo, para mim, aquela outra filosofia meramente para a cátedra, meramente para o texto e para a palavra não é filosofia, não tem verdadeiro valor nem espírito vivo (JWA 1,1, p. 339).
\end{abstract}

Refutando essa ideia de filosofia, Jacobi se opõe aos seus contemporâneos e constata que a diferença crucial entre eles é sua própria recusa em ser cartesiano, pois não parte da primeira pessoa e sim da terceira e nega que se possa pospôr um sum ao cogito. Descartes é simbolicamente importante e não à toa, ainda que de modo bastante controverso, Reinhard Lauth vê nele o "primeiro filósofo transcendental", já que tudo começaria com o eu (cogito) e não com as coisas (cogitatio), o princípio por excelência de toda epistemologia e logologia (Cf. LAUTH, 2001, p. 23).

No fundamento disso está, como diz W. von Humboldt, a ideia "universalmente difundida de que a filosofia é demonstrável apenas pela razão ou então não existe nenhuma” (JBW I/8, p. 404). É por partilhar essa ideia que Hegel e outros viram em Jacobi um grande pensador, porém o representante de uma filosofia impossível, não científica e subjetivista, de uma não-filosofia ou anti-filosofia.

Jacobi radicaliza essa posição e assume para si a não-filosofia, aceitando que se filosofia só existe na forma sistemática, a sua só poderia ser Unphilosophie. Contudo, essa Unphilosophie é um "sábio não-saber" (wissendes Nichtwissen) à maneira socrática e preferível às denominadas filosofias do eu à maneira cartesiana, que são um mero "saber insipiente" (nichtwissendes Wissen). Por fim, é na filosofia sistemática que corremos o risco de perder toda objetividade, com ela permanecermos apenas no saber que não sabe (nichtwissendes Wissen) ou na ignorância de que ignoramos. O conceito de personalidade é, portanto, uma salvaguarda contra a abstração ou subtração da objetividade do mundo e da realidade do sujeito, e a crença é o âmbito pré-, anti- e supra-reflexivo no qual deve se instalar a verdadeira filosofia. 


\section{Referências bibliográficas:}

HEGEL. "Enzyklopädie der philosophischen Wissenschaften im Grundrisse 1830". In: G. W. F. Hegel Werke 8. Frankfurt am Main: Suhrkamp, 1970.

. Fé e saber. Trad. Oliver Tolle. São Paulo: Hedra, 2007.

JACOBI, F. H. [JWA 1,1] "Über die Lehre des Spinoza in Briefen an Herrn Moses Mendelssohn”. In: Schriften zum Spinozastreit; 1,2: Anhang, hrsg. von Klaus Hammacher, Irmgard-Maria Piske, Hamburg/ Stuttgart: Meiner/Frommann-Holzboog, 1998.

. [JWA 2,1] "Brief an Fichte". In: Schriften zum Transzendentalen Idealismus. F. H. Jacobi Gesamtausgabe, hrsg. von Walter Jaeschke, Irmgard-Maria Piske, unter Mitarbeit von Catia Goretzki. Hamburg/Stuttgart: Meiner/Frommann-Holzboog, 2004.

. [JWA 2,1] "David Hume über den Glauben, oder Idealismus und Realismus. Ein Gespräch". In: Schriften zum Transzendentalen Idealismus. F. H. Jacobi Gesamtausgabe, hrsg. von Walter Jaeschke, IrmgardMaria Piske, unter Mitarbeit von Catia Goretzki. Hamburg/Stuttgart: Meiner/Frommann-Holzboog, 2004.

. [JWA 2,1] “Epistel über die Kantische Philosophie”. In: Schriften zum Transzendentalen Idealismus. F. H. Jacobi Gesamtausgabe, hrsg. von Walter Jaeschke, Irmgard-Maria Piske, unter Mitarbeit von Catia Goretzki. Hamburg/Stuttgart: Meiner/Frommann-Holzboog, 2004.

- [JWA 5,1] “Zufällige Ergiessungen eines einsamen Denkers in Briefen an vertraute Freunde. In: Schriften zum Transzendentalen Idealismus”. In: F. H. Jacobi Gesamtausgabe, hrsg. von Walter Jaeschke und Catia Goretzki. Hamburg/Stuttgart: Meiner/Frommann-Holzboog, 2007.

. [JBW I/8] F. H. Jacobi Briefwechsel: Juli 1788 bis Dezember 1790, hrsg. von Manuela Köppe. Stuttgart: Frommann-Holzboog, 2015.

. [JBW I/12] F. H. Jacobi Briefwechsel: 1799-1800, hrsg. von Manuela Köppe. Stuttgart: Frommann-Holzboog, 2018.

KANT. Kritik der reinen Vernunft. In: [AA] Akademieausgabe von Immanuel Kants Gesammelten Werken. [URL: https://korpora.zim.uni-duisburg-essen.de/kant/verzeichnisse-gesamt.html]

LAUTH, Reinhard. "Der Vorrang des transzendentalen Zugangs zur Philosophie”. In: Der Transzendentalphilosophische Zugang zur Wirklichkeit. Stuttgart: Frommann-Holzboog, 2001.

Recebido em 30 de junho de 2020. Aceito em 04 de agosto de 2020. 